\title{
CHAETOGLOBOSINAS PRODUZIDAS POR Chaetomium globosum, FUNGO ENDOFÍTICO ASSOCIADO A Viguiera robusta GARDN. (ASTERACEAE)
}

\author{
Luciano da S. Momesso, Cristina Y. Kawano, Patrícia H. Ribeiro, Auro Nomizo, Gustavo H. Goldman e Mônica T. \\ Pupo* \\ Faculdade de Ciências Farmacêuticas de Ribeirão Preto, Universidade de São Paulo, Av. do Café, s/n, 14040-903 \\ Ribeirão Preto - SP, Brasil
}

Recebido em 1/10/07; aceito em 7/5/08; publicado na web em 19/9/08

\begin{abstract}
CHAETOGLOBOSINS PRODUCED BY Chaetomium globosum, ENDOPHYTIC FUNGUS FOUND IN ASSOCIATION WITH Viguiera robusta Gardn (ASTERACEAE). Endophytes live in association with host plants during all or part of their life cycle without causing any apparent disease. They are considered outstanding and underexploited sources of novel bioactive compounds. Chaetomium globosum was isolated as an endophytic fungus from the healthy leaves of Viguiera robusta. C. globosum is a remarkable producer of chaetoglobosins, which are typically cytotoxic. In this work, chaetoglobosins B (1), D (2) and E (3) have been produced by the endophytic C. globosum strain. Chaetoglobosin B was evaluated against Jurkat (leukemia) and B16F10 (melanoma) tumoral cells and showed $89.55 \%$ and $57.10 \%$ of inhibition at $0.1 \mathrm{mg} \mathrm{mL}^{-1}$, respectively. Chaetoglobosin B also showed weak antibacterial activity against Staphylococcus aureus (MIC $120 \mu \mathrm{g} / \mathrm{mL}$ ) and Escherichia coli (MIC $189 \mu \mathrm{g} / \mathrm{mL}$ ).
\end{abstract}

Keywords: chaetoglobosins; Chaetomium globosum; endophytic fungus.

\section{INTRODUÇÃO}

Os microrganismos endofíticos podem ser detectados em um momento particular associados aos tecidos aparentemente saudáveis de plantas hospedeiras. ${ }^{1}$ Dentre os microrganismos endofíticos os fungos são os mais comumente associados às plantas. Eles vivem nos espaços inter ou intracelulares dos tecidos das plantas durante todo ou parte de seu ciclo de vida, sem causar sintomas aparentes de doenças. $^{2}$

Evidências sugerem que os fungos endofíticos possuem grande diversidade genética, implicando importância prática com relação à descoberta de novos metabólitos secundários bioativos. ${ }^{3}$ Muitos destes metabólitos possuem um grande potencial a ser utilizado na medicina, agricultura e indústria. Novos antibióticos, antimicóticos, imunossupressores e compostos anticâncer são esperados como metabólitos secundários produzidos por endofíticos. ${ }^{2}$

Os fungos endofíticos constituem uma importante e ainda pouco explorada fonte de novas substâncias químicas com potencial biológico, portanto, devem ser considerados em programas de bioprospecção. ${ }^{2,4}$

Resultados relevantes das pesquisas sobre o metabolismo secundário de fungos endofíticos incluem o isolamento do taxol, produzido por Taxomyces andreanae, fungo endofítico associado a Taxus brevifolia. ${ }^{5}$ Desde então, uma variedade de fungos endofíticos tem sido reconhecida pela habilidade de produzir o taxol. ${ }^{6} \mathrm{~A}$ vincristina, outro agente antineoplásico, foi isolada de um fungo endofítico não identificado associado a Catharanthus roseus. ${ }^{7}$ Outros importantes agentes anticâncer incluem a camptotecina, obtida de Rhizopus oryzae, fungo endofítico associado a Nothapodytes foetida ${ }^{8}$ e a podofilotoxina, produzida por Phialocephala fortinii, fungo endofítico de Podophyllum peltatum ${ }^{9}$ e também por Trametes hirusta, obtido de Podophyllum hexandrum. ${ }^{10}$

A seleção da planta hospedeira é crucial para isolamento de fungos endofíticos e obtenção de novos compostos bioativos. A planta

\footnotetext{
*e-mail: mtpupo@fcfrp.usp.br
}

deve ser selecionada principalmente com base em seu próprio meio ambiente, histórico etnobotânico, endemismo, longevidade e áreas de maior biodiversidade. ${ }^{2}$

O objetivo deste trabalho foi o isolamento, a identificação e avaliação biológica das substâncias produzidas por Chaetomium globosum, fungo endofítico associado a Viguiera robusta (Asteraceae), espécie endêmica no cerrado brasileiro. O gênero Viguiera é representativo da família Asteraceae e característico na produção de lactonas sesquiterpênicas com atividade antinflamatória e diterpenos com atividade sobre músculo liso. ${ }^{11}$ Chaetomium globosum foi isolado como endofítico das folhas de V. robusta. Esta espécie caracteriza-se pela produção de citocalasanas, que apresentam diversas atividades biológicas, incluindo ação citotóxica. ${ }^{12-15} \mathrm{O}$ cultivo de $C$. globosum levou ao isolamento das chaetoglobosinas B (1), D (2) e E (3).

\section{PARTE EXPERIMENTAL}

\section{Procedimentos experimentais gerais}

Os experimentos de RMN 1D e 2D foram obtidos em espectrômetro Bruker DRX-400 operando em $400 \mathrm{MHz}$ para o núcleo de ${ }^{1} \mathrm{H}$ e $100 \mathrm{MHz}$ para ${ }^{13} \mathrm{C}$, e em espectrômetro Bruker DRX-500 operando em $500 \mathrm{MHz}$ para ${ }^{1} \mathrm{H}$ e $125 \mathrm{MHz}$ para o núcleo de ${ }^{13} \mathrm{C}$. Os espectros de massas foram registrados em espectrômetro de massas ESI-EM Micromass Quattro LC ${ }^{\circledR}$, no modo electrospray. As análises cromatográficas por CLAE no modo analítico foram realizadas em equipamento Shimadzu SHIM-PAK com detector de arranjos de diodos, utilizando coluna analítica CLC - ODS (M) (250 x 4,6 mm). No modo preparativo, as análises por CLAE foram realizadas no mesmo aparelho, utilizando coluna semi-preparativa VP 250/10 Nucleosil 100-5 C18 (250 x 10 mm). Nas separações em CLAE reciclante foi utilizado equipamento Shimadzu LC-GAV (UV-SPD-10AV) e coluna preparativa Shodex Asahipak GS-310 26 (500 x 15 mm). Nas separações cromatográficas em coluna aberta foram utilizadas sílica gel $(0,060-0,200 \mathrm{~mm})\left(\right.$ Merck $\left.^{\circledR}\right)$ e sílica gel 60 silanizada $(0,063-0,200$ $\mathrm{mm})\left(\right.$ Merck $\left.^{\circledR}\right)$ como fases estacionárias. Nas separações por coluna 
líquida a vácuo (CLV) foi utilizada sílica gel 60H (45 $\mu \mathrm{m})\left(\right.$ Merck $\left.^{\circledR}\right)$ como fase estacionária.

\section{Material vegetal}

Folhas da espécie vegetal V. robusta Gardn. (Asteraceae) foram coletadas em outubro de 2002 no canteiro de plantas do Laboratório de Farmacognosia da Faculdade de Ciências Farmacêuticas de Ribeirão Preto - USP. Uma exsicata do material vegetal, identificado pelo Prof. Dr. J. N. Nakashima, encontra-se depositada no Herbário SPFR do Departamento de Biologia da Faculdade de Filosofia, Ciências e Letras de Ribeirão Preto - USP, sob o código FBC105.

\section{Isolamento da cepa fúngica}

O fungo endofítico foi isolado de folhas saudáveis de $V$. robusta. As folhas foram lavadas em água corrente e esterilizadas por imersão em etanol 70\% (3 min), NaClO 5\% (5 min), novamente em etanol 70\% (1 min), seguidas de lavagem em água destilada esterilizada (1 min). Após o processo de assepsia superficial, as folhas foram cortadas em pequenos pedaços de aproximadamente $0,5 \mathrm{~cm}$ de diâmetro, os quais foram incubados em placas de Petri com meio BDA (batata dextrose ágar), contendo o antibiótico terramicina $(50 \mathrm{mg} / \mathrm{mL})$ para evitar o crescimento de bactérias endofíticas. A espécie foi identificada através da seqüência de rDNA e é mantida em sílica gel (6-12 mesh) e slants de BDA a $4{ }^{\circ} \mathrm{C}$ no Laboratório de Enzimologia Industrial da Faculdade de Ciências Farmacêuticas de Ribeirão Preto - USP.

\section{Identificação do microrganismo}

O fungo foi crescido em meio líquido YPD (1\% de extrato de levedura, $2 \%$ de peptona, $2 \%$ de dextrose) em mesa agitadora shaker $\left(72 \mathrm{~h}, 30{ }^{\circ} \mathrm{C}, 120 \mathrm{rpm}\right)$, sendo então filtrado a vácuo, congelado em nitrogênio líquido e estocado a $-70^{\circ} \mathrm{C}$. O DNA genômico foi isolado utilizando a técnica de extração fenol-clorofórmio e então diluído em $100 \mu \mathrm{L}$ de água esterilizada e $1 \mu \mathrm{L}$ da solução de DNA foi utilizada para o procedimento de amplificação. O DNA foi quantificado por espectrofotometria por leitura da absorbância entre $260-280 \mathrm{~nm}$. A amplificação dos produtos foi verificada em gel de agarose a $1 \%$. O par de primers ITS3 e ITS4 foi utilizado para amplificar a porção maior de rDNA 5.8S e a região ITS2 adjacente. A amplificação por PCR foi realizada com um volume de $50 \mu \mathrm{L}$. Um $\mu \mathrm{L}$ do DNA genômico (500 ng), 2,5 $\mu \mathrm{L}$ de dNTP $4 \mathrm{mM}, 0,5 \mu \mathrm{L}$ de $5 \mathrm{U}$ de Amplitaq platinum Taq polimerase por $\mu \mathrm{L}$ e $5 \mu \mathrm{L}$ de tampão $10 \mathrm{X}(100 \mathrm{mM}$ Tris- $\mathrm{HCl}[\mathrm{pH} 8,3], 2 \mu \mathrm{L}$ de $\mathrm{MgCl}_{2} 50 \mathrm{mM}, 1 \mu \mathrm{L}$ de primers universais ITS3 e ITS 4 [ 21 pM] e $37 \mu \mathrm{L}$ de água destilada). A amplificação foi completada num termociclo sob as seguintes condições: $94{ }^{\circ} \mathrm{C}$ por 2 min, seguido por 35 ciclos de $94{ }^{\circ} \mathrm{C}$ por $1 \mathrm{~min}, 54{ }^{\circ} \mathrm{C}$ por $1 \mathrm{~min}, 72$ ${ }^{\circ} \mathrm{C}$ por 1 min e uma etapa final de $72{ }^{\circ} \mathrm{C}$ por $10 \mathrm{~min}$. Os produtos de PCR foram purificados em coluna Qiagen. A análise da seqüência inteira de DNA do produto de PCR obtido com os primers universais de fungo ITS3 e ITS4 específicos para genes de rDNA foi realizada para confirmar a identificação da espécie. Foi então realizado o seqüenciamento automático em ambas as direções usando um primer de amplificação inicial e a seqüência alinhada de DNA resultante foi analisada com o software Sequencher. A comparação da seqüência isolada foi realizada com a seqüência presente no GenBank, utilizando busca avançada de BLAST. ${ }^{16}$

\section{Cultivo do microrganismo e obtenção dos extratos brutos}

C. globosum foi repicado em 13 placas de Petri contendo meio BDA e incubado por 7 dias a $30^{\circ} \mathrm{C}$. A cultura fermentativa foi reali- zada em duas etapas. Inicialmente, 3 fragmentos de ágar de aproximadamente $0,5 \mathrm{~cm}$ de diâmetro foram transferidos das placas de Petri para cada um dos 13 frascos de Erlenmeyers (1 L) contendo $200 \mathrm{~mL}$ de meio de cultivo pré-fermentativo seed, ${ }^{17}$ os quais foram mantidos em mesa agitadora a $120 \mathrm{rpm}$ e $30{ }^{\circ} \mathrm{C}$ por $48 \mathrm{~h}$. Posteriormente, a massa micelial obtida foi filtrada em ambiente asséptico e transferida para 13 frascos de Erlenmeyers (2 L) contendo $400 \mathrm{~mL}$ de meio de cultivo Czapek, ${ }^{18}$ os quais foram incubados em mesa agitadora por 144 $\mathrm{h}$, a $120 \mathrm{rpm}$ e $30^{\circ} \mathrm{C}$. Ambos os meios de cultivo foram previamente submetidos à esterilização em autoclave a $121^{\circ} \mathrm{C}$ e 1 atm de pressão por $15 \mathrm{~min}$. Após o término do cultivo, a cultura foi filtrada a vácuo em funil de Büchner e o fluido da cultura foi submetido à partição líquido-líquido com AcOEt. A evaporação do solvente forneceu 600,0 $\mathrm{mg}$ do extrato bruto acetoetílico (CGLA).

\section{Isolamento dos constituintes químicos}

O extrato bruto CGLA $(600,0 \mathrm{mg})$ foi submetido a uma CLV, utilizando-se como fase estacionária sílica gel $60 \mathrm{H}$ e como fases móveis hexano 100\%, hexano-AcOEt 19:1, 9:1, 17:3, 4:1, 7:3, 1:1, 3:7, 1:4, 1:9, 1:19 (v/v), AcOEt 100\%, MeOH-AcOEt 1:1 (v/v) e $\mathrm{MeOH} 100 \%$ (150 mL cada fração), fornecendo 14 sub-frações. A sub-fração CGLA9 $(250,0 \mathrm{mg}$ ) foi submetida a uma coluna aberta utilizando-se como fase estacionária sílica gel silanizada e como fase móvel acetona-água (1:1), fornecendo na sub-fração 5 a substância 1 (25,2 mg). A sub-fração CGLA10 (72,0 mg) foi também submetida à coluna aberta sob as mesmas condições, fornecendo 8 sub-frações. As subfrações CGLA10.4 (19,7 mg) e CGLA10.5 (19,0 mg) foram submetidas à CLAE reciclante em sistema isocrático $\mathrm{MeOH} 100 \%$, fornecendo 5 e 10 sub-frações, respectivamente. Do fracionamento da sub-fração CGLA10.4 foi obtida a substância $2(2,0 \mathrm{mg})$ e a partir da sub-fração CGLA10.5, novamente a substância $\mathbf{1}$ (2,0 mg). A sub-fração CGLA11 (79,0 mg) foi submetida à coluna aberta em sílica sinalizada, utilizando-se como fase móvel MeOH-água (1:1), fornecendo 4 sub-frações. A sub-fração $4(54,1 \mathrm{mg})$ foi submetida à CLAE semi-preparativa, utilizando-se como fase estacionária C-18, fase móvel MeOH- $\mathrm{H}_{2} \mathrm{O}$ (1:1), vazão de $5 \mathrm{~mL} / \mathrm{min}$ e $\lambda$ de 225 $\mathrm{nm}$, fornecendo 5 sub-frações, dentre elas a substância $3(1,0 \mathrm{mg}) \mathrm{e}$ novamente as substâncias $\mathbf{1}(1,0 \mathrm{mg})$ e $\mathbf{2}(1,0 \mathrm{mg})$.

\section{Avaliação da atividade citotóxica}

A substância 1 foi submetida ao bioensaio de citotoxicidade frente às linhagens tumorais Jurkat (leucemia T) e B16F10 (melanoma). A amostra foi solubilizada em DMSO/meio RPMI (1:100) sendo este diluente utilizado como controle negativo. Como controle positivo foi utilizado o cloridrato de gencitabina. Para avaliar a atividade citotóxica foi utilizado o método colorimétrico de citotoxicidade pelo 3-(4,5-dimetil tiazol 2-il) 2,5-difenil brometo de tetrazólio (MTT). ${ }^{19}$ A avaliação da atividade citotóxica foi determinada por espectrofotometria, utilizando filtro de interferência de $540 \mathrm{~nm}$.

\section{Determinação da concentração inibitória mínima (CIM)}

A concentração inibitória mínima (CIM) foi determinada pelo método de microdiluição em microplaca utilizando cloreto de trifeniltetrazólio como revelador. Foram preparadas soluções das substâncias isoladas contendo $1 \mathrm{mg} / 500 \mu \mathrm{L}$ em DMSO. Em seguida, foram transferidos $100 \mu \mathrm{L}$ desta solução para tubo contendo $100 \mu \mathrm{L}$ de caldo triptona soja. Com o auxílio de uma alça de platina esterilizada, as culturas de $24 \mathrm{~h}$ dos microrganismos indicadores, desenvolvidas no ágar triptona soja, foram transferidas para tubos contendo $10 \mathrm{~mL}$ de solução salina esterilizada. Foram procedidas as diluições suces- 
sivas das suspensões microbianas (Escherichia coli (ATCC25922) e Staphylococcus aureus (ATCC25923)) em solução salina e por fim em caldo triptona soja, de modo a fornecer um inóculo de $10^{4} \mathrm{UFC} /$ $\mathrm{mL}$. Em uma microplaca esterilizada de 96 orifícios foi aplicado um total de $100 \mu \mathrm{L}$ da mistura do caldo triptona soja, da solução da substância 1 e das suspensões dos microrganismos. A substância 1 foi avaliada em concentrações que variaram de 400 a 1,563 $\mu \mathrm{g} /$ $\mathrm{mL}$. Foram realizados também os controles positivo, negativo e de esterilidade do meio de cultivo. As microplacas foram incubadas a $37{ }^{\circ} \mathrm{C}$ por $24 \mathrm{~h}$. Posteriormente, foram adicionados em cada orifício $40 \mu \mathrm{L}$ de cloreto de trifeniltetrazólio $\left(\right.$ Sigma $\left.^{\circledR}\right)$ preparado em solução aquosa $(7 \mathrm{mg} / \mathrm{mL})$. As microplacas foram reincubadas por $30 \mathrm{~min}$, sendo então observado o aparecimento de cor. A ausência de cor nos orifícios foi interpretada como ausência de crescimento microbiano (microrganismo sensível à amostra testada). Foram utilizados antibióticos padrão como controles positivos, penicilina $\mathrm{G}$ para $S$. aureus e estreptomicina para E. coli..$^{20}$

\section{RESULTADOS E DISCUSSÃO}

O estudo químico do extrato bruto AcOEt obtido do cultivo em Czapek produzido pelo fungo endofítico C. globosum resultou no isolamento de três citocalasanas (1-3). A identificação destas substâncias foi realizada com base nos dados espectroscópicos obtidos (RMN ${ }^{1} \mathrm{H}$ e ${ }^{13} \mathrm{C}$, DEPT, $g$ COSY ${ }^{1} \mathrm{H}-{ }^{1} \mathrm{H}, g \mathrm{HMQC}, g \mathrm{HMBC}$ e EM) e comparação com dados disponíveis na literatura. ${ }^{13,23}$ As citocalasanas são micotoxinas que se caracterizam quimicamente pela presença de um anel peridroisoindol-1-ona altamente substituído e fundido a um anel macrocíclico (Figura 1). A natureza do substituinte em C-3 indica o aminoácido que originou a citocalasana, através da ligação com a cadeia policetídica precursora dos anéis peridroisoindol-1-ona e macrocíclico. Quando a citocalasana é biossintetizada a partir do triptofano, a sub-classe de metabólitos é denominada chaetoglobosinas. ${ }^{21}$ Fenilalanina (originando citocalasinas) e leucina são aminoácidos que freqüentemente são também encontrados nas citocalasanas.

As principais características estruturais do anel macrocíclico, em geral de 11 ou 13 membros, incluem presença de até três oxidações em C-19 (álcool ou cetona), C-20 (álcool ou cetona) e C-22 (geralmente cetona); presença de até três ligações duplas $\left(\Delta^{13,14}, \Delta^{17,18}\right.$, $\Delta^{21,22}$ ); presença de grupamentos metílicos em C-16 (Me-24) e C-18 (Me-25). No anel peridroisoindol-1-ona as principais modificações estruturais encontradas são presença de ligação dupla $\Delta^{5,6}, \Delta^{6,12}$ ou $\Delta^{6,7}$; presença de epóxido entre C-6 e C-7; presença de hidroxila em C-7; presença de grupamentos metílicos em C-5 (Me-11) e C-6 (Me-12). Mais de 30 chaetoglobosinas já foram isoladas e identificadas, e os dados de difração de raios-X permitiram o estabelecimento da estrutura cristalográfica das chaetoglobosinas. ${ }^{22}$ Portanto, apesar da complexidade estrutural destas substâncias, é relativamente simples identificar a classe química com base na análise dos dados de RMN ${ }^{1} \mathrm{H}$ e ${ }^{13} \mathrm{C}$, e, através da comparação com os dados da literatura, ${ }^{13,23}$ estabelecer a estrutura da chaetoglobosina.

A análise dos dados de $\mathrm{RMN}{ }^{1} \mathrm{H}, \mathrm{RMN}{ }^{13} \mathrm{C}$ (32 sinais) e EM ([M+H] $]^{+}$ 529) possibilitou a proposição da fórmula molecular $\mathrm{C}_{32} \mathrm{H}_{36} \mathrm{~N}_{2} \mathrm{O}_{5}$ para a substância 1 (IDH 16) (Figura 1). O espectro de RMN ${ }^{1} \mathrm{H}$ apresentou sinais característicos de chaetoglobosinas. Os sinais do anel indólico do triptofano foram observados em $\delta 8,25$ (sl, NH); 7,51 (dl, $J=8,1 \mathrm{~Hz}, \mathrm{H}-4$ ') $, 7,38$ (dl, $J=8,1 \mathrm{~Hz}, \mathrm{H}-7$ ') , 7,16 (s, H-2') , 7,09 (ddd, $J=8,1 ; 7,8 ; 1,0 \mathrm{~Hz}, \mathrm{H}-6$ ') e 7,01 (ddd, $J=8,1 ; 7,8 ; 1,0 \mathrm{~Hz}, \mathrm{H}-5$ '). Os sinais de hidrogênios metílicos foram observados em $\delta 1,00$ (d, $J=6,6$ Hz, H-24), 1,33 (sl, H-11), 1,40 (sl, H-25) e 1,65 (sl, H-12). Os deslocamentos químicos e valores das constantes de acoplamento para os hidrogênios vinílicos em $\delta 7,65$ (d, $J=16,4 \mathrm{~Hz}, \mathrm{H}-22), 6,76$ (d, $J=16,4 \mathrm{~Hz}, \mathrm{H}-21$ ), 6,18 (ddd, $J=15,4 ; 9,8 ; 1,5 \mathrm{~Hz}, \mathrm{H}-13$ ) e 5,18 (ddd, $J=15,4 ; 10,1 ; 3,5 \mathrm{~Hz}, \mathrm{H}-14$ ) indicaram a presença de duas ligações duplas com geometria $E$ no anel macrocíclico, geralmente encontradas nas chaetoglobosinas entre C-21 e C-22 e entre C-13 e C-14. O sinal em $\delta 5,57$ (dl, $J=8,8, \mathrm{H}-17$ ) evidenciou a presença de dupla $\Delta^{17,18}$, também comum nas chaetoglobosinas. Foram ainda observados dois sinais referentes a hidrogênios carbinólicos em $\delta$ 3,91 (dd, $J=10,6 ; 1,0$ Hz, H-7) e 5,09 (s, H-19). O espectro de RMN ${ }^{13} \mathrm{C}$ apresentou três sinais de carbonilas, uma referente à carbonila de amida do anel peridroisoindol-1-ona em $\delta 174,6$ e outros dois referentes às carbonilas do anel macrocíclico em $\delta$ 201,0 (C-23) e 202,7 (C-20). As correlações observadas nos experimentos COSY, HMQC e HMBC permitiram a completa e inequívoca atribuição de todos os sinais de carbonos e hidrogênios da molécula. Os dados de RMN ${ }^{1} \mathrm{H}$ e ${ }^{13} \mathrm{C}$ da substância $\mathbf{1}$ estão de acordo com os dados publicados previamente para a chaetoglobosina B. ${ }^{13,14,23}$

As configurações relativas foram propostas com base na literatura, a partir de dados da estrutura da chaetoglobosina A obtida por difração de raios- $X .^{22}$

Os dados de RMN ${ }^{1} \mathrm{H},{ }^{13} \mathrm{C}$, HMQC e HMBC para a substância 2 foram muito semelhantes aos observados para 1, que apresentou o mesmo íon molecular no EM $\left([\mathrm{M}+\mathrm{H}]^{+} 529\right)$. Porém, apenas três sinais referentes a grupamentos metílicos foram observados. O sinal em $\delta$ 1,65 (sl, H-12) observado para 1 está ausente no espectro de RMN ${ }^{1} \mathrm{H}$ de 2 , e dois sinais de hidrogênios vinílicos estão presentes em $\delta$ $5,30(\mathrm{~m}, 1 \mathrm{H})$ e 5,05 $(\mathrm{m}, 1 \mathrm{H})$, ambos ligados ao carbono em $\delta 113,6$, conforme correlação observada no HMQC. O sinal dos hidrogênios metílicos em $\delta 1,10$ (d, $J=6,8 \mathrm{~Hz}$ ) indica acoplamento com H-5 ( $\delta$ $2,90, \mathrm{~m}$ ). Estas alterações sugerem ligação dupla $\Delta^{6,12} \mathrm{em} 2$ (Figura 1). Os dados para os anéis macrocíclico e indólico foram os mesmos observados para 1 . Os dados de $\mathrm{RMN}{ }^{1} \mathrm{He} \mathrm{e}^{13} \mathrm{C}$ obtidos para 2 estão de acordo com os dados publicados para a chaetoglobosina D..$^{23}$

A substância 3 (Figura 1) também apresentou dados de RMN uni e bidimensionais compatíveis com os dados das chaetoglobosinas. Os dados para os anéis peridroisoindol-1-ona e indólico foram compatíveis com aqueles previamente observados para a substância 1; as modificações foram observadas nos sinais referentes ao anel macrocíclico de 3. Os sinais referentes aos hidrogênios vinílicos $\mathrm{H}-21$ e $\mathrm{H}-22$, e respectivos carbonos, não foram observados, sugerindo redução da ligação dupla $\Delta^{21,22} \mathrm{em} \mathrm{3}$. Adicionalmente, a correlação observada no HMBC entre os hidrogênios metílicos H-25 ( $\delta 1,82$, d, $J=1,4 \mathrm{~Hz}$ ) e o carbono carbonílico em $\delta 204,8$ (C-19) sugere que em 3 a carbonila está em C-19 e o grupamento hidroxílico em C-20, originando a chaetoglobosina E. Os dados de RMN ${ }^{1} \mathrm{H}$ obtidos para 3 estão em concordância com os dados publicados para a chaetoglobosina E. ${ }^{14-23}$
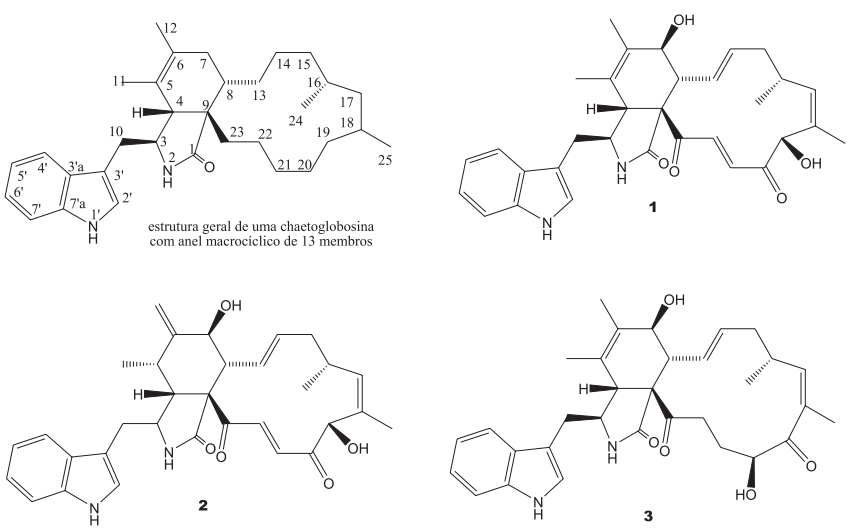

Figura 1. Estrutura geral de uma chaetoglobosina com anel macrocíclico de 13 membros e das substâncias 1-3 produzidas por C. globosum 
Os dados de RMN ${ }^{1} \mathrm{H}$ e ${ }^{13} \mathrm{C}$ para as substâncias 1-3 estão apresentados na Tabela 1. As chaetoglobosinas já foram isoladas das culturas de diversos fungos de solo, fitopatógenos, de ambiente hospitalar e de coleções comerciais, pertencentes aos gêneros $\mathrm{Ca}$ lonectria ${ }^{24}$ Cylindrocladium, ${ }^{25}$ Discosia,${ }^{25}$ Iplodia,${ }^{26}$ Penicillium $^{27} \mathrm{e}$ Phomopsis. ${ }^{28}$ Porém, a maioria das chaetoglobosinas foi isolada de espécies de Chaetomium. ${ }^{29}$ Recentemente, as chaetoglobosinas C, F, E, e penocalasina $\mathrm{A}$, além da nova chaetoglobosina $\mathrm{U}$, foram também isoladas de uma cepa endofítica de C. globosum. Novas chaetoglobosinas continuam a ser identificadas de fungos de solo $^{29}$ e marinhos. ${ }^{30}$ Citocalasinas derivadas da fenilalanina foram recentemente isoladas de fungo endofítico no Brasil. ${ }^{3}$

As citocalasanas são reconhecidas por suas notáveis atividades biológicas. O nome citocalasana tem origem nas palavras gregas cytos (célula) e chalasis (relaxação) e refere-se aos efeitos celulares destas substâncias. As citocalasanas inibem o movimento e a quebra citoplasmática de células de mamíferos, efeitos atribuídos direta ou indiretamente à interação destas substâncias com a proteína actina. ${ }^{21,29}$

Há vários relatos ${ }^{12-15}$ da proeminente atividade citotóxica in vitro para as citocalasanas, o que foi experimentalmente confirmado pelo ensaio de citotoxicidade realizado com a substância $\mathbf{1}$ frente às linhagens de células tumorais Jurkat (leucemia T) e B16F10 (melanoma). A substância 1 apresentou inibições de 89,55\% para a linhagem Jurkat e de $57,10 \%$ para B16F10 na concentração de $0,1 \mathrm{mg} / \mathrm{mL}$, enquanto que nessa mesma concentração o cloridrato de gencitabina, utilizado como controle positivo, não apresentou inibição do crescimento celular. Na concentração de $0,5 \mathrm{mg} / \mathrm{mL}$, os valores observados foram de 86,51 e $85,14 \%$ para as linhagens Jurkat e B16F10, respectivamente, enquanto que o controle positivo inibiu em 37,93 e 38,27\% o crescimento celular. Já na concentração de 1,0

Tabela 1. Dados de RMN de ${ }^{1} \mathrm{H}^{\#}(400 \mathrm{MHz})$ e ${ }^{13} \mathrm{C}(125 \mathrm{MHz})$ da chaetoglobosina B (1), chaetoglobosina D (2) e chaetoglobosina E (3) em $\left(\mathrm{CD}_{3}\right)_{2} \mathrm{CO}, \delta(\mathrm{ppm})$

\begin{tabular}{|c|c|c|c|c|c|c|}
\hline & 1 & & 2 & & 3 & \\
\hline & $\delta{ }^{1} \mathrm{H}$ & $\delta{ }^{13} \mathrm{C}$ & $\delta{ }^{1} \mathrm{H}$ & $\delta^{13} \mathrm{C}^{\S}$ & $\delta{ }^{1} \mathrm{H}$ & $\delta^{13} \mathrm{C}$ \\
\hline 1 & - & 174,6 & - & 172,5 & - & 175,8 \\
\hline 2 & - & - & $*$ & - & $7,24(\mathrm{sl})$ & - \\
\hline 3 & $3,60(\mathrm{tl})$ & 56,6 & $3,53(\mathrm{~m})$ & 53,3 & $3,56(\mathrm{~m})$ & 59,3 \\
\hline 4 & $3,31(\mathrm{sl})$ & 49,3 & $3,58(\mathrm{~m})$ & 46,4 & $3,06(\mathrm{~m})$ & 51,3 \\
\hline 5 & - & 127,8 & $*$ & 33,0 & - & 127,6 \\
\hline 6 & - & 134,8 & - & $*$ & - & 134,6 \\
\hline 7 & $3,91(\mathrm{dd}, 10,6 ; 1,0)$ & 70,4 & $3,96(\mathrm{~m})$ & 69,9 & $3,85(\mathrm{dl}, 7,0)$ & 69,9 \\
\hline 8 & $2,00(\mathrm{~m})$ & 53,7 & $*$ & 50,8 & $2,10(\mathrm{~m})$ & 53,6 \\
\hline 9 & - & 63,1 & - & $*$ & - & 63,4 \\
\hline 10 & $\begin{array}{c}2,87(\mathrm{dd}, 14,1 ; 6,1) / \\
2,64(\mathrm{dd}, 14,1 ; 6,1)\end{array}$ & 34,2 & $\begin{array}{c}2,78(\mathrm{dd}, 14,7 ; 6,7) / \\
2,93(\mathrm{dd}, 14,7 ; 6,7)\end{array}$ & 34,8 & $\begin{array}{l}2,97(\mathrm{dd}, 8,9 ; 6,5) / \\
2,59(\mathrm{dd}, 14,0 ; 8,9)\end{array}$ & 33,1 \\
\hline 11 & $1,33(\mathrm{sl})$ & 18,3 & $1,10(\mathrm{~d}, 6,8)$ & 16,1 & $1,24(\mathrm{sl})$ & 18,0 \\
\hline 12 & $1,65(\mathrm{sl})$ & 15,5 & $5,30(\mathrm{~m}) / 5,05(\mathrm{~m})$ & 113,6 & $1,61(\mathrm{sl})$ & 15,3 \\
\hline 13 & $6,18(\mathrm{ddd}, 15,4 ; 9,8 ; 1,5)$ & 130,2 & $5,93(\mathrm{ddd}, 14,9 ; 9,9 ; 1,7)$ & 128,4 & $6,43(\mathrm{ddd}, 15,2 ; 9,3 ; 1,8)$ & 130,6 \\
\hline 14 & $5,18(\mathrm{ddd}, 15,4 ; 10,1 ; 3,5)$ & 136,5 & $5,18(\mathrm{ddd}, 14,9 ; 3,8 ; 0,6)$ & 136,8 & $5,24(\mathrm{ddd}, 15,2 ; 11,0 ; 2,3)$ & 135,9 \\
\hline 15 & $2,30(\mathrm{~m}) / 2,08(\mathrm{~m})$ & 43,2 & $1,62(\mathrm{~d}, 1,7) / 1,83(\mathrm{~d}, 1,7)$ & 42,4 & $2,43(\mathrm{~m}) / 2,14(\mathrm{~m})$ & 42,6 \\
\hline 16 & $2,56(\mathrm{~m})$ & 33,9 & $2,28(\mathrm{~m})$ & 32,6 & $2,80(\mathrm{~m})$ & 34,8 \\
\hline 17 & $5,57(\mathrm{dl}, 8,8)$ & 140,9 & $5,56(\mathrm{~d}, 9,4 ; 1,3)$ & 140,6 & $6,38(\mathrm{dl}, 8,1 ; 1,5)$ & 150,4 \\
\hline 18 & - & 134,2 & - & 132,1 & - & 134,6 \\
\hline 19 & $5,09(\mathrm{~s})$ & 83,9 & $5,02(\mathrm{~s})$ & 81,9 & - & 204,8 \\
\hline 20 & - & 202,7 & - & 201,8 & $4,86(\mathrm{~m})$ & 72,7 \\
\hline 21 & $6,76(d, 16,4)$ & 137,5 & $6,36(d, 16,7)$ & 133,1 & $1,94(\mathrm{~m}) / 1,85(\mathrm{~m})$ & 31,3 \\
\hline 22 & $7,65(d, 16,4)$ & 135,6 & $7,88(d, 16,7)$ & 137,4 & $3,12(\mathrm{~m}) / 3,03(\mathrm{~m})$ & 38,9 \\
\hline 23 & - & 201,0 & - & 197,3 & - & 210,5 \\
\hline 24 & $1,00(\mathrm{~d}, 6,6)$ & 22,4 & $0,95(\mathrm{~d}, 6,6)$ & 21,5 & $1,07(\mathrm{~d}, 6,5)$ & 20,8 \\
\hline 25 & $1,40(\mathrm{sl})$ & 11,9 & $1,34(\mathrm{~d}, 1,3)$ & 11,1 & $1,82(\mathrm{~d}, 1,4)$ & 13,1 \\
\hline 1 ' & $8,25(\mathrm{sl})$ & - & $10,04(\mathrm{sl})$ & - & $10,16(\mathrm{sl})$ & - \\
\hline $2^{\prime}$ & $7,16(\mathrm{~s})$ & 125,4 & $7,12(\mathrm{sl})$ & 123,4 & $7,13(\mathrm{sl})$ & 125,1 \\
\hline $3^{\prime}$ & - & 112,3 & - & 111,3 & - & 112,5 \\
\hline 3'a & - & 129,4 & - & 127,2 & - & 129,1 \\
\hline $4^{\prime}$ & $7,51(\mathrm{dl}, 8,1)$ & 120,2 & $7,51(\mathrm{dl}, 7,8)$ & 118,9 & $7,54(\mathrm{~d}, 7,8)$ & 119,8 \\
\hline $5^{\prime}$ & 7,01 (ddd, 8,1; 7,8; 1,0) & 120,7 & 7,01 (ddd, 7,8; 7,1; 1,0) & 120,4 & $7,02(\mathrm{ddd}, 8,2 ; 7,8 ; 1,1)$ & 120,4 \\
\hline $6^{\prime}$ & $7,09$ (ddd, 8,$1 ; 7,8 ; 1,0)$ & 123,2 & 7,07 (ddd, 7,8; 7,1; 1,3) & 123,0 & $7,10(\mathrm{ddd}, 8,2 ; 7,8 ; 1,1)$ & 122,9 \\
\hline 7 ' & $7,38(\mathrm{dl}, 8,1)$ & 113,2 & $7,34(\mathrm{dl}, 7,8)$ & 111,5 & $7,40(\mathrm{~d}, 7,8)$ & 113,0 \\
\hline 7'a & - & 138,4 & - & $*$ & - & 138,7 \\
\hline
\end{tabular}

\# Multiplicidades e constantes de acoplamento $(J)$, em Hz, entre parênteses. ${ }^{\S}$ Dados obtidos em $\mathrm{CDCl}_{3}$ * Sinal não atribuído. As atribuições foram realizadas através dos dados obtidos nos experimentos de HMQC e HMBC. 
$\mathrm{mg} / \mathrm{mL}$, enquanto o controle positivo inibiu em 41,45 e $38,87 \%$ o crescimento celular das linhagens Jurkat e B16F10, respectivamente, a substância 1 apresentou 85,30 e 81,01\% de inibição. As Figuras 2 e 3 ilustram os resultados obtidos nos ensaios, que mostraram a elevada atividade citotóxica desta substância frente às células tumorais. As chaetoglobosinas C, F, E, U, e penocalasina, isoladas de cepa endofítica de $C$. globosum, também apresentaram ação citotóxica na linhagem tumoral humana KB. ${ }^{32}$ Citocalasanas derivadas da fenilalanina, obtidas de fungos do gênero Phoma, também apresentaram atividade frente a células FT210 de carcinoma de rato ${ }^{33}$ e frente à linhagem tumoral humana HT29. ${ }^{34}$

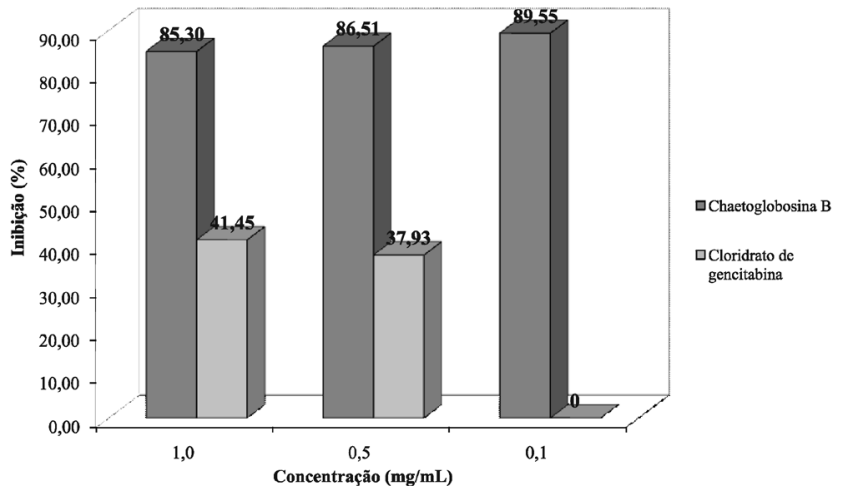

Figura 2. Avaliação da atividade citotóxica da chaetoglobosina B (1) em linhagem celular Jurkat (leucemia T)

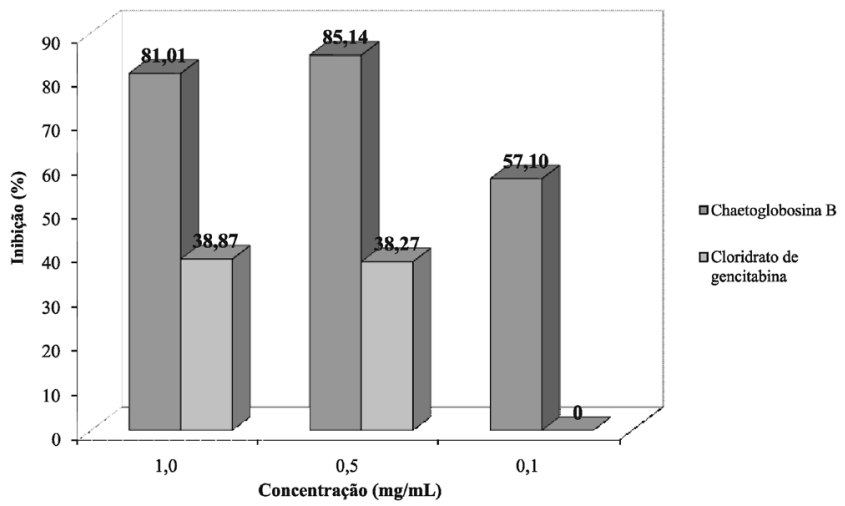

Figura 3. Avaliação da atividade citotóxica da chaetoglobosina B (1) na linhagem celular B16F10 (melanoma)

A atividade antibiótica da substância $\mathbf{1}$ foi avaliada pelo método de microdiluição com a finalidade de determinar a concentração inibitória mínima (CIM) frente a S. aureus e E. coli. A substância 1 apresentou fraca atividade antibacteriana, com CIM de $120 \mu \mathrm{g} / \mathrm{mL}$ para $S$. aureus e CIM de $189 \mu \mathrm{g} / \mathrm{mL}$ para E. coli.

A maioria das atividades biológicas descritas para as chaetoglobosinas foi avaliada em modelos in vitro. ${ }^{12-15}$ Ensaios de toxicidade experimental em modelos animais são menos numerosos, mas evidenciaram que a chaetoglobosina A apresentou toxicidade após admistração por via oral 8 vezes inferior quando comparada à admistração por via parenteral. ${ }^{21}$

As chaetoglobosinas A e $\mathrm{C}$, juntamente com outras micotoxinas, agentes químicos e particulados, têm sido apontadas como responsáveis pela diminuição da qualidade do ar em interiores, causando a "Síndrome dos Edifícios Doentes". ${ }^{35}$ Ainda, as chaetoglobosinas A e $\mathrm{C}$ foram detectadas em produtos derivados de frutas ${ }^{27}$ e castanhas ${ }^{36}$ contaminados com espécies de fungos do gênero Penicillium.

A elevada citotoxicidade dificulta a utilização das citocalasanas como candidatos a protótipos para o desenvolvimento de fármacos.
Porém, estas substâncias são extremamente valiosas em experimentos de biologia química, ${ }^{37}$ principalmente por inibirem a divisão celular, originando células multinucleadas. ${ }^{13-15}$

\section{CONCLUSÃO}

A obtenção de chaetoglobosinas reforça a hipótese de simbiose entre o fungo endofítico e a planta hospedeira, uma vez que estas substâncias bioativas poderiam auxiliar na adaptação do hospedeiro ao meio ambiente. Além disso, C. globosum parece ser um bom produtor de chaetoglobosinas, uma vez que linhagens de origem de solo, endofíticas e de origem marinha, cultivadas em diferentes meios de cultura líquidos e sólidos, produziram substâncias desta classe. A linhagem endofítica descrita neste trabalho também produziu chaetoglobosinas quando cultivada em diferentes meios, incluindo meio sólido arroz e meio líquido de malte. Os resultados obtidos ilustram o potencial biotecnológico dos fungos endofíticos na busca por novos compostos bioativos e/ou ferramentas úteis em biologia química.

\section{AGRADECIMENTOS}

À FAPESP (Fundação de Amparo à Pesquisa do Estado de São Paulo) pelas bolsas de mestrado e doutorado concedidas a L. S. Momesso (processos 02/06144-0 e 04/06399-3) e pelo auxílio financeiro concedido nos projetos 03/07535-5 e 04/07935-6 (Programa BIOprospecTA-Biota-FAPESP). Os autores também agradecem o Laboratório de Biologia Molecular da Faculdade de Filosofia, Ciências e Letras de Ribeirão Preto-USP, sob responsabilidade da Profa. Dra. M. H. Goldman, e à aluna de doutorado A. C. Quiapim pelo suporte no seqüenciamento do DNA fúngico. Os agradecimentos são ainda estendidos à C. C. de Macedo (FCFRP-USP), pelo suporte técnico, e ao Prof. Dr. N. P. Lopes (FCFRP-USP), pela obtenção dos EM.

\section{REFERÊNCIAS}

1. Schulz, B.; Boyle, C.; Mycol. Res. 2005, 109, 661

2. Strobel, G.; Daisy, B.; Castillo, U.; Harper, J.; J. Nat. Prod. 2004, 67, 257.

3. Hellwig, V.; Grothe, T.; Mayer-Bartschmid, A.; Endermann, R.; Geschke, F. U.; Henkel, T.; Stadler, M.; J. Antibiot. 2002, 55, 881.

4. Borges, W. S.; Pupo, M. T.; J. Braz. Chem. Soc. 2006, 17, 929; Gunatilaka, A. A. L.; J. Nat. Prod. 2006, 69, 509; Zhang, H. W.; Song, Y. C.; Tan, R. X.; Nat. Prod. Rep. 2006, 23, 753; Clardy, J.;Walsh, C.; Nature 2004, 432, 829.

5. Stierle, A.; Strobel, G.; Stierle, D.; Science 1993, $260,214$.

6. Strobel, G. A.; Crit. Rev. Biotech. 2002, 22, 315.

7. Yang, X.; Zhang, L.; Guo, B.; Guo, S.; Zhongcaoyao 2004, 35, 79.

8. Puri, S.C.; Verma, V.; Amna, T.; Qazi, G. N.; Spiteller, M.; J. Nat. Prod. 2005, 68, 1717.

9. Eyberger, A. L.; Dondapati, R.; Porter, J. R.; J. Nat. Prod. 2006, 69, 1121.

10. Puri, S. C.; Nazir, A.; Chawla, R.; Arora, R.; Riyaz-ul-Hasan, S.; Amna, T.; Ahmed, B.; Verma, V.; Singh, S.; Sagar, R.; Sharma, A.; Kumar, R.; Sharma, R. K.; Qazi, G. N.; J. Biotechnol. 2006, 122, 494.

11. Ambrosio, S. R.; Tirapelli, C. R.; Da Costa, F. B.; De Oliveira, A. M.; Life Sci. 2006, 79, 925.

12. Sharma, R. P.; Salunkhe, D. K.; Mycotoxins and Phytoalexins, CRC Press: Boca Raton, 1991.

13. Sekita, S.; Yoshihira, K.; Natori, S.; Kuwano, H.; Chem. Pharm. Bull. 1982, 30, 1629

14. Cole, R. J.; Cox, R. H.; Handbook of toxic fungal metabolites, Academic Press: New York, 1981.

15. Binder, M.; Tamm, C.; Angew. Chem., Int. Ed. 1973, 12, 370.

16. Henry, T.; Iwen, P. C.; Hinrichs, S. H.; J. Clin. Microbiol. 2000, 38, 1510 . 
17. Jackson, M.; Karwoswski, J. P.; Humphrey, P. E.; Kohl, W. L.; Barlow, G. J.; Tanaka, S. K.; J. Antibiot. 1993, 46, 34.

18. Alviano, C. S.; Farbiarz, S. R.; Travassos, L. R.; Angluster, J.; Souza, W.; Micopathologia 1992, 119, 17.

19. Mosman, T.; J. Immunol. Methods 1983, 65, 55.

20. Andrews, J. M.; J. Antimicrob. Chemother. 2001, 48, 5.

21. Natori, S.; Yahara, I. Em Mycotoxins and phytoalexins; Sharma, R. P.; Salunkhe, D. K., eds.; CRC Press: Boca Raton, 1991, cap. 12.

22. Silverton, J. V.; Akiyama, T.; Kabuto, C.; Sekita, S.; Yoshihira, K.; Natori, S.; Tetrahedron Lett. 1976, 17, 1349.

23. Sekita, S.; Yoshihira, K.; Natori, S.; Chem. Pharm. Bull. 1983, 31, 490.

24. von Wallbrun, C.; Luftmann, H.; Bergander, K.; Meinhardt, F.; J. Gen. Appl. Microbiol. 2001, 47, 33.

25. Danoso, R.; Rivera-Sagredo, A.; Hueso-Rodriguez, J. A.; Élson, S. W.; Nat. Prod. Lett. 1997, 10, 49.

26. Spondlin, C.; Tamm, C.; Helv. Chim. Acta 1988, 71, 1881.

27. Andersen, B.; Smedsgaard, J.; Frisvad, J. C.; J. Agric. Food Chem. 2004, $52,2421$.

28. Burlot, L.; Cherton, J. C.; Convert, O.; Correia, L.; Dennetiere, B.;
Spectroscopy 2003, 17, 725.

29. Jiao, W.; Feng, Y. J.; Blunt, J. W.; Cole, A. L.; Munro, M. H. J.; J. Nat. Prod. 2004, 67, 1722.

30. Christian, O. E.; Compton, J.; Christian, K. R.; Mooberry, S. L.; Valeriote, F. A.; Crews, P.; J. Nat. Prod. 2005, 68, 1592; Iwamoto, C.; Yamada, T.; Ito, Y.; Minoura, K.; Numata, A.; Tetrahedron 2001, 57, 2997.

31. Cafêu, M. C.; Silva, G. H.; Teles, H. L.; Bolzani, V. S.; Araújo, A. R.; Young, M. C. M.; Pfenning, L. H.; Quim. Nova 2005, 28, 991.

32. Ding, G.; Song, Y. C.; Chen, J. R.; Xu, C.; Ge, H. M.; Wang, X. T.; Tan, R. X.; J. Nat. Prod. 2006, 69, 302.

33. Kakeya, H.; Morishita, M.; Onozawa, C.; Usami, R.; Horikoshi, K.; Kimura, K.; Yoshihama, M.; Osada, H.; J. Nat. Prod. 1997, 60, 669.

34. Alvi, K. A.; Nair, B.; Pu, H.; Ursino, R.; Gallo, C.; Mocek, U.; J. Org. Chem. 1997, 62, 2148.

35. Fogle, M. R.; Douglas, D. R.; Jumper, C. A.; Straus, D. C.; Mycopathologia 2007, 164, 49.

36. Overy, D. P.; Seifert, K. A.; Savard, M. E.; Frisvad, J. C.; Int. J. Food Microbiol. 2003, 88, 69.

37. Pupo, M. T.; Gallo, M. B. C.; Vieira, P. C.; Quim. Nova 2007, 30, 1446. 